\title{
The Effects of Conceptual Metaphor in Advertising Discourse between Chinese and Western Cultures
}

\author{
Dongyan $\mathrm{Li}^{1,}$ a and Qingfeng $\mathrm{Guo}^{2, \mathrm{~b}}$ \\ ${ }^{1}$ College of Humanities and Social Sciences, Hei Longjiang Bayi Agricultural University, Daqing, Hei \\ Longjiang, China, 163319; \\ ${ }^{2}$ College of Information Technology and Sciences, Hei Longjiang Bayi Agricultural University, \\ Daqing, Hei Longjiang, China, 163319; \\ aredsun_2002@163.com, bgqfafg@126.com
}

Keywords: Advertising discourse; Conceptual metaphor; Effects; Culture

\begin{abstract}
As a mode of cognition, conceptual metaphor builds a cognitive relation between two cognized fields or concepts through the thinking of the cognitive body. Different conceptions are caused by different cultural variations in which Chinese and English conceptual metaphor systems are generated. The paper attempts to make an analysis of conceptual metaphor regarding the effects of advertising discourse hoping to help us better understand cultural factors and origins in different societies to promote the smoother communication between each other.
\end{abstract}

\section{Introduction}

Conceptual metaphor, with the systems of its own, is widely employed in both English and Chinese. While the similar life experience results in similar conceptual metaphors in Chinese and English language, the metaphors of these two different languages also show their own national characteristics and cultural connotations under the influence of certain factors resulting from different cognitive and socio-cultural backgrounds. "For that there is too much temporal and geographical variation in how humans conceptualize. The complement that is required is an awareness of the role of culture.'[1] Considering the discrepancies between the culturally-loaded views held by westerners and Chinese, the article attempts to elaborate the culturally-specific meaning within the theory of conceptual metaphor considering the effects of advertising discourse, which claims that "metaphors are grounded in our constant interaction with our physical and cultural environments" and "the most fundamental values in a culture will be coherent with the metaphorical structure of the most fundamental concepts in the culture."[2]. Likewise, since the interpretation of conceptual metaphor can reflect the way Chinese and westerners think differently to a great extent, the culture unique to China and western countries is most likely to be revealed simultaneously.

\section{Literature Review}

Metaphor in essence is the fact that one can use one thing to understand and experience another thing [2]. Lakoff and Johnson and other followers think that metaphor is ubiquitous and is the basic way for people to do thinking; They put forward the basic concept of metaphor and conceptual metaphor, laying the foundation of metaphor in cognitive linguistics. From the perspective of cognitive relevance theory, some researchers discuss metaphor, thinking the shift from literal meaning to metaphor meaning is a gradual process with the difference being the amount of implied meaning. The real meaning is determined from these meanings [3] [4]. Goatly [3] distinguished the 13 effects of metaphor: a. fill vocabulary vacancy; b. interpretation and estimation; c. rebuild experience; $d$. debate by analogy and wrong inference; e. ideology; f. emotion attitude; g. modify, hide and exaggerate; $h$. cultivate intimacy; I. humor and game; j. figuratively summon to take action or to solve the problem; $\mathrm{k}$. form discourse; 1 . fiction; $\mathrm{m}$. enhance memory, salience and information. As the purpose of the association, they may present themselves in a degree of focus. Conceptual metaphor, the basic 
concept of cognitive linguistics, in advertising discourse in the process of generating and processing plays an immeasurable cognitive and psychological role in the addresser and the addressee between Chinese and western cultures.

\section{The Universality of Conceptual Metaphor and Its Cultural Basis}

Just as human beings have the same cognitive systems and similar living experiences, so metaphors in different cultures have similar cognitive bases. We know metaphor is a useful tool we use to understand the world we are in, the cognitive process of obtaining the image produced by metaphor must be universal in this respect, because there is something in common in the way that we human beings form conceptions and perceive the things we see. In other words, though cultural variations exist in different languages, there are conceptual metaphors that seem to be universal.

For instance, we can find that the idea of "happiness" is expressed by the concept of "up", i.e. HAPPY IS UP in both Chinese and English.

Metaphors found in western cultures such as North American cultures do seem to share the same kind of images perceived from the metaphors in Chinese culture. The concept of "one family and one world" has been generally accepted as a kind of common understanding among the world countries, especially in the field of water reservation, industrial pollution, rare animal protection etc.

In the nation-wide campaign of water reservation in Chinese culture, the government put up an advertisement on CCTV, with the slogan of "The last drop of water in the world that remains is going to be our tears." This advertisement is a metaphor vividly depicting the horrifying scene we are facing if the problem of over-consumption and pollution of the limited water resources our lives are depending on is ignored. The natural resource reservation campaign has called attention to the water reservation problem by creating a scene of people of the world living on the same continent as a big family. Also it's true in western cultures.

\section{The Effects of Conceptual Metaphor in Advertising Discourse}

Advertisements are usually regarded as an especially practical genre with its characteristics being short and sweet in which the advertiser is the addresser while the target audiences are the addressee. One of the qualified and successful advertising standards is whether the advertisements meet the principle of AIDA: a) Attention, b) Interest, c) Desire, d) Action [5]. It is obvious that a successful advertising can first arouse target audience's attention and their interest in the advertised products or services or the images of adverting companies. The coming step is the desire to purchase with the ultimate aim being achieved by taking actions of buying regardless of the factors such as the nationality and the geography. Nevertheless, one can use conceptual metaphor to increase the successful chances of achieving the effects of advertising, which are expounded as follows.

Novel Effect. In order to attract the target audience, advertisers often adopt the strategy of novel metaphors to interest them in promoting products or services, impressing the audience and influencing their buying behavior, which is intended to increase the effect of language expression [6].

To be novel is to cater to the audience's curiosity and imitation, arouse the resonance of the audience. For instance, the United States savings bank advertises "the best book in the world - your own passbook". This advertisement is novel and unique, refreshing. Similarly, as New York City bank - "city never sleep". City bank of New York spent heavily to build a set of perfect infrastructure and highly efficient and stable application system, to ensure that any time someone answering customer calls, truly a "never sleep". Cleverly embedded with the brand name to the advertisement, its theme is clear with the core advantage aptly expressed in New York City bank, deepening the memory of brand name and service advantages.

But in the pursuit of uniqueness, the advertisers had better pay attention to the choice of the appropriate associations. The advertisement of Red bull drinks is "car needs gas; I drink red bull", although there is a certain correlation between energy in car and a person, that sounds bad and lets a person feel uncomfortable. 
Concise Effect. Leech [7] pointed out that when the message is short, significance and intact, the encoding and decoding process will save time and effort. That is to say, concentration is the essence. So does an advertisement because metaphor ads conform to the creation of the KISS (Keep It Short and Sweet) principle, which are easy to repeat, memorize and circulate on the basis of focused meaning.

In fact, the ingenious nature of metaphor is that it in the context, a word is both unique and economical. So in the specific context, a word in metaphor ads often can express meanings multiple words communicate. Because in this kind of metaphor metaphors are more specific than ontology, which make advertisement become short, beautiful, economical and practical.

For example: A diamond lasts forever (De Bierres). The Chinese is "diamonds are forever, A forever". The advertisements of diamond reads catchy, rendering an artistic conception, not only revealing the true value of a diamond, but also from another level elevating the value of love to enough height. Love is a very abstract concept originally, but when compared to a diamond, the specific image of the words appeared in the audience's mind, which makes the target audience easy to associate them with love, this is the greatest feeling. Though short and plain, the advertising discourse has concise and vivid effect, shortening the distance between the advertisers with the audience's heart.

Meaning-created Effect. The meaning of advertising metaphor is created from the perspective of linguistics. We know that metaphor is an important way of language development and change, if carefully analyzed; the etymology of every word can find the shadow of the metaphor [8].

The word formations in metaphor are noun into verbs, adjectives, and participles, etc. As in the "Behind that healthy smile, there's a Crest kid" (Crest toothpaste), healthy is metaphorical adjective in advertising, because it is used often with such words collocation as body, food, diet and skin and rarely co-occurs with smile at the same time. Here healthy smile metaphor gives a person a fresh breath and the cheerful mood will begin from healthy teeth. "At peacetime, save a drop of water; in trouble, you'll have the Pacific" (Pacific insurance). In the advertisement, "a drop of water" and "Pacific" uses the metaphor. At ordinary times, to himself and his family "a drop of water" (metaphors) input for a small amount of money (ontology) to buy insurance, do it for a rainy day, in case one should encounter great trouble in future, one can have "Pacific"(metaphors) for timely help.

Through metaphor people can use the old vocabulary to talk about the new things, as long as the context shares similarity to more visually reflect the essence and characteristics of things, especially for metaphor ads. Still we know that the same symbol or form may invoke different images and arrive at different effects under different cultures.

Cultural Effect. In today's information age, advertising has reached deeply into every aspect of social life; it uses concise and vivid language to intensively and vividly show the characteristics and quality of commodity, to express the desire of the consumer and requirements; It uses such rich emotional color language to attract the audience that resonates with the target audience, not only making people understand their commodities, trust it, but also becoming a kind culture of enterprise and society.

For example, "give computer a Pentium chip" (Intel). The Intel Company since 586, the running speed of computer is defined by the Pentium. Intel is said to have had a 5\% rebate for each big computer company to launch its own Pentium brand for the sake of their products and packaging with the words "Intel inside". The advertising discourse highlights the brand and better reflects the driving force of the Pentium microprocessor and surging, which has evolves into a world known enterprise culture. And another instance is "the love of Unicom, like a Chinese knot, connects hearts universally" (China Unicom). Unicom logo is the image of a Chinese knot, which is full of affinity, with high quality service and low price it gradually develops in the competition. Unicom integrating the logo and brand name into the advertising discourse, from the appearance to the harmony spirit, reflect the enterprise culture.

Generally speaking, metaphors found in the Western cultures such as the European and North American cultures do seem to share the same kind of images perceived from the metaphors in the Eastern cultures such as the Chinese culture. The concept of "one family and one world" has been 
generally accepted as a kind of common understanding among the world countries, especially in the field of water reservation, industrial pollution, rare animal protection etc. A similar example is the advertisement of environmental protection concerning the improper cultivation of land in China. A public advertisement once put up by the government reads "Leave a piece of farmland for our grandchildren." So, again, a metaphor of "family" is introduced to let people realize the importance of environmental protection.

Yet the confession we have to make here is that there are certain kinds of metaphors that are culturally unique. There exist differences between conceptual metaphors and the relevant metaphorical representations in Chinese and western cultures, which resulted from the different cognitive and sociocultural backgrounds.

Metaphors are no doubt culturally restricted and bound, for they are the representations of the cultural heritage of the society into which the language users are born. Take one of the major metaphors "Society as Marketplace" for example, the meaning of the metaphor can only be fully perceived and understood by those who are familiar with the emergence and development of the commercial culture such as the commercial culture that is seen in the American society in the last few decades, especially after the Second World War.

\section{Conclusion}

The paper mainly discussed the four effects of conceptual metaphor in advertising discourse and the conclusion is that the use of conceptual metaphor as a means of cognitive tool to construe advertising discourse better with the effects of advertisements being novel, concise, meaning-created and cultural, attaining the result with half effort. Metaphor in essence is a thinking tool human beings understand and perceive the world around us, and its other features and effects in advertisements especially in Chinese and western cultures still need further mining.

\section{References}

[1] C.J. Forceville: Non-verbal and multimodal metahphor in a cognitivist framework: Agendas for research. In G. Kristiansen, M. Achard, R. Dirven \& F.J. Ruiz (Ed.), Cognitive Linguistics: Current Applications and Future Perspectives (Mouton de Gruyter, USA 2006, p. 372-402).

[2] Lakoff, G. \& Johnson, M: Metaphors We Live By (The University of Chicago Press, USA 2003).

[3] Goatly, a: Species of Metaphor in Written and Spoken Varieties. In M. Ghadessy (Ed.), Register Analysis Theory and Practice (Printer, England 1993, p. 110-148).

[4] Holme, R: Grammatical Metaphor as a Cognitive Construct. In A. M. Simon-Vandenbergen, M. Taverniers, \& L. J. Ravelli (Ed.), Grammatical Metaphor: Views from Systemic Functional Linguistics (John Benjamins, Holland 2003, p. 391-415).

[5] Guo-wen, Huang: The theory and practice of discourse analysis-study on advertising discourse (Shanghai foreign language education press, China 2001).

[6] DingFang, Shu: The study of metaphor (Shanghai foreign language education press, China 2002).

[7] Leech, G: Principles of Pragmatics (Longman, England 1983).

[8] Hester, M: The Meaning of Poetic Metaphor (Mouton de Gruyter, Germany 1967). 